\title{
Vitality And Tragedy Of Peri-Urban Socio-Cultural Patterns
}

\author{
Efa Tadesse Debele \\ E-mail:efatdss@gmail.com(Efa T.D.) \\ Co-author: Gutema Imana Keno \\ E-mail:Imanake@yahoo.com(Gutema I.K.)
}

\begin{abstract}
Until recently, academia has largely neglected the vitality and tragedy that urbanization has been potentially posed in the peri-urban areas. Several studies indicated that urbanization causes both vitalities and tragedies in the area where the process is taking place. However, the vitalities and tragedies of peri-urban sociocultural patterns, that induced owing to urbanization process, are largely missing. The empirical studies indicated that urbanization process cause upsides and downsides not only within urban perse but also on the its peripheries. This study dedicates to study the vitality and tragedy of urbanization on the farming community surrounding Finfinne with particular emphasis on socio-cultural patterns. The paper employs both quantitative and qualitative research method to investigate the socio-cultural vitality and tragedy of peri-urbanization process. The baseline finding revealed that socio-cultural patterns of the community were well structured and stable. However, unchecked urbanization with alarming rate induced impacts on the overall patterns of the farming community. Accordingly, socio-cultural patterns have been dismantled. For example, first language abandonment turned out to be worrisome. The ever increasing heterogenity challenged the local identity survival and progress. The local social values, norms, and community spirit faced serious challenges. Despite its negative aspects, urbanization impacted availability of infrastructures and social amenities into peri-urban area. This indicates that necessary cautionary measures should be taken before farming community eviction. In addition, awareness should be created among the community on how to adapt new urban life style. Controlling urban sprawling, deliberative and smart urban planning are forwarded as key recommendations based on the empirical study undertaken.
\end{abstract}

Keywords: Peri-urbanization, Vitalities and tragedies, socio-cultural patterns, farming community

\subsection{Background of the Study}

\section{INTRODUCTION}

A number of alternative terms have been used to describe the geographical area where farming community live close to urban. For example, Mandere (2010) enumerated as the urban fringe, the periphery, inner rural and rural commuting zone. It can also be further described as an area adjacent to built up areas of high population concentration, urban, and zone where traditional farming activities come into conflict with alternative economic, residential, and recreational interest. Douglas (2001) delineated peri-urbanization as a dynamic process where areas located at the outskirts are gradually changed into urban character. Furthermore, Maconachie and Binns (2006) defined peri-urban areas in the context of Africa as area with great dynamism and competition for basic resources and characterized with a "blurring" between rural and urban. Peri-urban interface refers to the urban fringe and geographic edge of cities which play an important role as a physical place for the movement of goods and services and a transition place from rural to urban context. This process results in different socio-cultural impacts on the farming community's pre-existing overall patterns. It forms new patterns there at the expense of the pre-existing patterns. In most cases, the urban lifestyle and folk lifestyle are incompatible. For example, Spengler (1922) as cited by Flanagan (2010) mentioned that all urban cultures became alien to its hinterland. He mentioned that the peasant could not understand drastic and progressive urban culture because urban environment developed its own culture which denies nature. The scenario of urbanization process always undergoes dynamic changes. These days, urbanization is a rising trend observed all over the world, specially it is rising at an alarming rate in study area mainly due to its closeness to the capital city or Finfinne.

The purpose of this study was to investigate the socio-cultural impacts of urbanization on the farming community living in the area surrounding Finfinne. The study area is highly undergoing a drastic and extensive transformations which is induced by urbanization. In fact, the study area is composed of urban, rural, semiurban and semi-rural areas. Nowadays, the towns in the area surrounding Finfinne are expanding to their peripheries. As a result, several rural villages closer to these towns have been changed into urban setting. This conversion is multidimensional; it can be social, cultural, economic, political and physical conversion. This 
process is called peri-urbanization resulting from its setting. The urbanisation process of towns in the area surrounding Finfinne in general, and its sprawling or horizontal expansion in particular results in several changes. In the aforementioned zone, urbanization process is increasing rapidly. The study area is highly experiencing industrial establishments, real estate investment and residential construction process which is stimulated by leasehold land policy framework. The local farming community included in this study in general, and indigeneous farmer households in particular were the concerns of this study. This is due to the farming community's exposure to the urbanization impacts in the study area. However, these impacts were not rigorously studied, as long as the researcher of this study observed. This was the key rationale for conducting the study. The researcher believed that the detailed nature of these impacts deserve a rigorous study. Moreover, there is a research gap in investigating and indicating the existence of such social phenomenon and its impacts. This study was dedicated to inspect the theme and come up with resilient and viable remedies based on the results of empirical data analysis.

\subsection{Statement of the Problem}

The urbanisation process of towns in area surrounding Finfinne in general and its horizontal expansion in particular resulted in both vitality and tragedy impacts. These impacts are serious and multidimensional. The urban expansion caused socio-cultural impacts on the nearby farming community. Eventhough urbanisation brought opportunities in the area, it also has posed several negative impacts. This trend is very tangible in the study area. But, it was not rigorously investigated. Urban sprawl increases socio-cultural conversion into urban style for different adaptation purpose. This reduced the original socio-cultural and exposed farmers to new socio-cultural patterns. This leaves farmers rootless and exposes them to insecure living conditions. Displacement and eviction are the main impacts of urbanization process in the study area. This tendency poses cultural disruption and community dismantling. Thus, the current urban sprawl trend creates fortune for settlers and harm the majority of the indigeneous community members who are incapable of adjusting themselves to urban character partly due to their background. The community lacks modern technical skills and modern lifestyle skills which aggravate the severity of urbanization impacts on the community. This indicates the existing urbanization trend does not harmonize with the status of the community. The alleged urban development projects provoked the local identity loss and first language use abandonment which become the community's day to day concern. But, these problems were not seriously studied and that is why this study was conducted.

The study area is expected to face several complicated and tremendous impacts unless the impacts are identified and controlled before escalation. The detail of these impacts were not critically studied. So this research was conducted to address this gap. The open spaces in the vicinity of the towns Surrounding Finfinne are highly converted to other use without taking into account the present community's needs and the coming generation's fate. For this reason, the community in vicinities of towns of Oromia Special Zone Surrounding Finfinne become exposed to unfamiliar socio-cultural impacts which need meticulous investigation. Hence, this study considered the socio-cultural impacts of urbanisation on the farming community in the Oromia Special Zone Surrounding Finfinne in order to disclose the realities regarding the impacts of Urban sprawl.

\subsection{Objectives of the Study}

The general objective of this research is to investigate vitality and tragedy of peri-urban socio-cultural patterns in the areas surrounding Finfinne.

In addition, specific objectives of the research are:

1. to examine vitality of peri-urban socio-cultural patterns in the areas surrounding Finfinne,

2. to investigate tragedy of peri-urban socio-cultural patterns in the areas surrounding Finfinne,

\section{CONCEPTUAL FRAMEWORK OF THE STUDY}

Currently, the process of urbanization is undergoing with an alarming rate. This urbanisation process in general and its horizontal expansion so called urban sprawl in particular has become a global agenda. In fact, in different countries it has different forms but commonly urban sprawl shares common patterns in terms of its causes and consequences. The impacts that come up with urbanization process in general and urban sprawl in particular is multidimensional. It causes socio-cultural impacts on the peri-urban farming community. Urbanisation can destruct traditional cultural values and norms. This creates the situation of normlessness in peri-urban farming community. Urbanisation can also breakdown the strong social bond between family and kinship network as well as community at large. It stimulates individualistic culture. Peri-urban farming community can be amalgamated with settlers. The newly emerged social pattern is artificial or fragile pattern. Most often their communication medium may be via dominant national language. This leads to the disuse of local language of the community. Urbanisation can cause social identity loss through eviction of the farmers from their land and social pattern. This eviction results in the disintegration and segregation which facilitates 
their loss of communal sense or belongingness. Once they lose this sentiment, automatically social identity will be at risk. In fact, the issue of urbanization and its impacts is too complex and wide to address. Thus, in order to make it more understandable, it is presented in figure 1 diagrammatically:

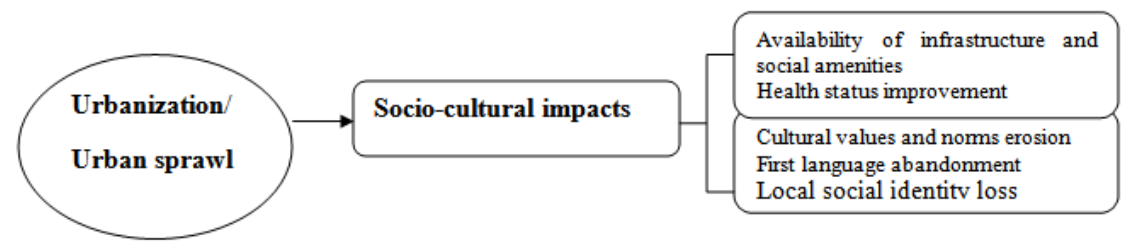

Figure 1:Research Scheme (Conceptual framework) of the study

\section{RESEARCH METHODOLOGY}

\subsection{Description of the Study Area}

This study was conducted in the Oromia Special Zone Surrounding Finfinne. Finfinne, the capital city of Oromia state, was established nearly 129 years ago. Since its establishment, Finfinne has been stretching its size by including the surrounding rural areas. Starting from Tullu Dalati, the hill on which the residence of the Prime Minister is found, Finfinne stretched to Akaki in the East, Gulale in the West, Garji in the South and Entoto in the North. Recently, Oromia Special Zone Surrounding Finfinne was formed to control the urban sprawl of Finfinne city to the lands of the surrounding farming community.

This Zone was created in 2008 by Oromia state. It was formed from parts of North Shewa, East Shewa, South West Shewa and West Shewa Zones. The Zone comprises 8 towns found around Finfinne, namely: Burayu, Dukam, Galan, Holeta, Laga Tafo-Laga Dadhi, Sabata, Sandafa, Sululta and surrounding peri-urban vicinities which were the focus of this study. Currently, the peri-urbanization process is going on at an alarming rate, in the Zone. Hence, the motive behind this study was to identify the impacts of urbanization on the periurban farming community.

Figure 2:Map of the study area

\subsection{Methods of data collection}

In this study, mixed method research design was employed. The quantitative data was collected by cross sectional survey method through interview schedule. This shared the larger portion of the respondents since it makes the study to be more objective, accurate and generalizable. Besides, a qualitative data was gathered to enrich the research by obtaining data in depth and address culturally sensitive issues that not

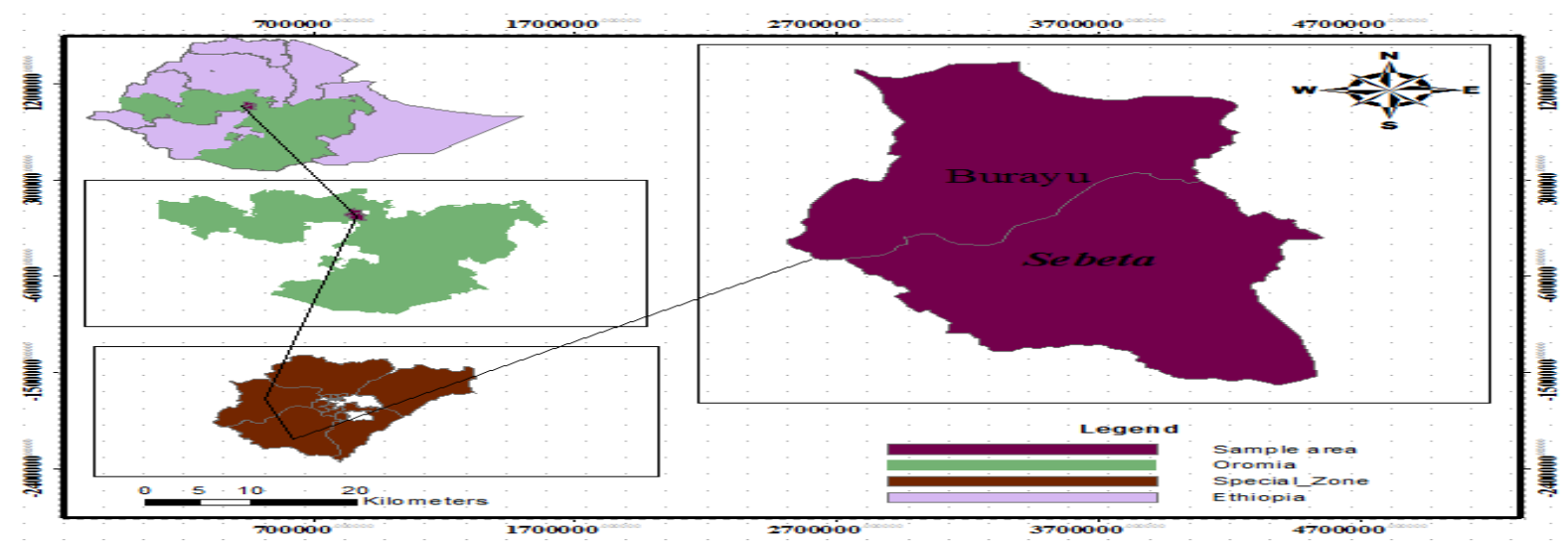

addressed by quantitative approach, and qualitative data was accessed through focus group discussion and key informants interview. 384 sample households were drawn by proportional sampling techniques for household survey.

\subsection{Data Processing and Analysis}

The quantitative and qualitative data obtained through the predetermined data collection tools, were analyzed using appropriate methods of analysis as explained below.

\subsubsection{Quantitative data}

The quantitative data were coded and entered into a computer for analysis. The stata version 11 software was used as analysis tool. Both descriptive and inferential type of statistical analysis were used in the

DOI: 10.9790/0837-22040594103 www.iosrjournals.org $\quad 96 \mid$ Page


quantitative data analysis. The association between variables was checked or tested by chi-square tests. This test statistic determined the correlation between urbanization and its impacts. Its principle stated that when the value of chi-square is greater than critical value and p-value is less than the value of the significance level (alpha), we reject our null hyphothesis which claim independence of two variables and accept the alternative hyphothesis that claim the association or correlation between variables. The normality of variable distribution was tested and found that the variables were approximately and normally distributed. As a result, the chi-square test was used to test the association between variables so as to judge wether two variables are related or independent of each other. Accordingly, the null hypotheses will be rejected if and only if chi-square value is greater than critical value and p-value less than alpha value other wise the null hypothesis will not be rejected (Bluman, 2009).

\subsubsection{Qualitative data}

The qualitative data was analyzed by organizing, summarizing and interpreting the data collected qualitatively. In other words, qualitative data was analyzed descriptively in the form of narration.

\section{RESULTS AND DISCUSSIONS \\ 4.1. Socio-Cultural Impacts of Urbanization on Peri-urban Community 4.1.1. First Language Use}

The extent of first language use in the homogeneous community is very high. The farming community members in the study area descend from the same linguistic background so that regularly communicate using their first language. However, as the area is getting converted to urban setting their homogenity may be no more dominant and it can impact the extent of first language use.

Furthermore, from table 1, it can be easily understood that the majority of the respodents do not frequently use first language. Out of the sample households $18.75 \%$ respondents reported that they use first language most frequenntly whereas $19.53 \%$ respondents reported as they use moderately and $61.72 \%$ of them reported that they use their first language less frequently. The frequency or rate of first language use become lower as the extent of urbanization increases. The reduction in the number of language speakers in the long run threaten the survival and progress of the language chiefly in the study area. This may lead to language abandonment. Similar to this result, Nutter (2010) reported that minority languages may fall into disuse as the dominant European language or dominant local language takes over in the urban community. The community members who are totally swallowed up by urban character are less likely to use their first language due to unavailability of first language speakers at nearby as usual. The urban setting constitutes enormous linguistic diversity that constraint the prevalence of one language. Similar to this result Thou (2010) reported that due to diverse land uses, most population here comprises of heterogeneous groups including original residents, farmers, migrant residents, recreational land users, industrial users, investors and speculators, developers and builders. On the other hand, the farming community members live at the periphery have more likely to practice their language frequently due to dominant number of the indigenous farming community members. In addition, FGD discussants mentioned that they are forced to use non-first language in order to communicate with nonhome-grown individuals, particularly in social institutions, social services areas and business centers. Some of the respondents also confirmed that their children faced difficulties because they cannot find prefered schools in the urban where they learn through their first language starting from kindergarten to preparatory school. This happened due to the expansion of the private schools which uses non-local language as medium of instruction. Most of the key informants interviewees explained that they suffered from travelling their children long distance to attend school which uses their first language as a medium of instruction. This give us an idea about the seriousness of the problem which is becoming demanding problem.

\subsubsection{Local Social Values, Norms and Community Spirit}

The farming community in the study area had their own distinct social values, norms and community spirit. The members of the farming community strongly expected to hold and protect their social values, norms and community spirit. However, as the farming community exposes to competing alien social values, norms and artificial social solidarity, they may tend to deviate from their own. It is clearly depicted in table 1 that the majority of the community hold less on the local social values, norms and community spirit. Out of the sample households about half $(61.72 \%)$ of the respondents reported that they have lost the community spirit and less respect local social value and norms whereas $38.28 \%$ of the participants reported that they well protect and retain with local social values, norms and collective spirit. The farming community members merged into the urban are more exposed to alien social values, norms thereby the lose of community spirit. They started to pursue different lifestyle. The members of the community tend to give more emphasis for the private concern than for the common interest. This upsets the traditional communal life. In line with this result, Ferdinand Tonnies (n.d) stated that as society grew, get industrialized and moved to cities, social ties weakened and become more individualistic oriented. The farming community members who live nearby urban setting could 
not protect their earlier social values, norms and community spirit. This happened logically in order to adapt the urban lifestyle which more possibly contradict with previous lifestyle.

On the other hand, the farming community members who live at the periphery could protect and sustain their social values, norms and community spirit. Yet, in the long run, this farming community members are vulnerable too. Even if the community members possibly lose their own insteady acclimatize the vitality of alien noble values and norms proven crucial for the survival and prosperity of the community. The adaptation process should be alert and rational otherwise assimilation and cultural imperialization need to be denounced. In line with this result, Bhatta (2010) reported that the inhabitants may lose the sense of community as their population size and diversity rises drastically. The members of the community are inclined to adapt new artificial social pattern. This creates antisocial behaviors and promotes individualistic cultures in this manner stimulates normlessness. In so doing urbanization can erode community's earlier pattern and replace by fragile one. Similar to this result, Nutter (2010) states that urbanization upsets traditional social patterns. The Focus Group Discussion discussants also mentioned that the local social values and norms lost power as alien social values and norms erodes traditional one and more people gradually deviating from the traditional social values. They added that disrespect for the local social values and immitating non-local one destruct the community spirit of unity. In line with this, Haregewoin (2005) reported that the intimate social ties exists due to close proximity among community will be declined as the result of urbanization.

\subsubsection{Local Identity Loss}

The farming community in the study area had strong affiliation and solidarity. The majority of the members of the community unreservedly trust each other and have the same psychological make up. The community members concieve each other as they are one and belong to the same cultural group. As a result, the members are easily identified from the outgroup. However, as the urban setting engulf this community may possibly no more have distinct identity

From table 1 it can be easily recognized that half of the sample households $(61.72 \%)$ reported that they have fear of losing their identity while $38.28 \%$ of respondents reported that they do not have threat of losing their identity. The community members live in the urban setting are more likely to be swallowed up by urban pattern and less likely to protect and to prosper their identity. The community members who evicted from their base obliged to lose their identity. They lost the integral cultural elements that retain their identity. The urban pattern constitutes different individuals and social groups from different identity backgrounds.

Thus, urbanization triggers the local identity lose through cultural fragmentation and assimilation. On the other hand, the community living at the periphery of urban setting are more likely to sustain and protect their identity. The community who are not evicted also more likely to secure their identity. The local identity loss become more threatened as the extent of urbanization increases. This exposed the community to tension and frustration. Similar to this result, Tönnies [1887] 1940, 74 cited by Flanagan (2010) stated that everybody is by himself isolated and exists a condition of tension against all others. This leads to the feeling of rootlessness.

\subsubsection{Health Status}

The health status of the farming community refers to the overall health condition of farming households, their livestocks, neighboring environments, etc. The health status of the community can be promoted and facilitated by living in a healthy environment and consuming health promoting services. Farming communities are unfamiliar to urban environment and health care services. This exposure to unfamiliar urban environment can alter health condition of the farming community.

The fact in the study area testifies the same thing. Even if urbanization created health opportunities, the health status of the community showed insignificant improvement as the extent of urbanization increases. In view of that as depicted in table 1, it can easily be understood that inconsiderable number of the households (51.04\%) reported that they experienced health condition improvement whereas (48.96\%) of them reported that their health status become worse off. The farming community members who properly utilise the available health care services can promote their health status. The farmers who live in the healthy environment are more likely to enhance their health status. On the other hand, the farming community members who do not access health care services and do not properly utilise health promoting lifestyle more likely to be exposed to health crisis. The farming community members who live near to industries that produce polluttants more likely to suffer from health catastrophe. The community members who engage in factories employment may face health risk that can be caused by toxic gas and contaminated chemicals. This possibly affect their skin, breathing system and other thin-skinned body parts. In line with this, Bhatta (2010) reported that air pollution poses severe breathing problems, skin diseases and other health problems which affects health status of human being and other species. The FGD discussants and key informants interviewees also reported that nowadays their health status is at risks. Most of them said that some of their livestock died and family's health become vulnerable to the harmful sewages that industries releases. 


\subsubsection{Infrastructure and social facilities}

The farming community members might lack infrastructure and social facilities in their environment because they were not merged into urban setting. However, as the farming community exposes to urban environment they may come across to infrastructures and social services. Additionally, as it can be seen from table 1 more than half $(54.69 \%)$ of the community do have access to infrastructure and social facilities at their local which enable them to cope up with competition of the life in the urban setting. On the other hand, a considerable number $(45.31 \% \%)$ of the households reported that they do not have access to infrastructure and social services. The community members living adjacent to urban core are more likely to get access to roads, electricity, clean water, school, health care, banking services, etc. On the other hand, the community living at the periphery are less likely to get access to infrastructures and social services. The farming community members who live nearby industries also more likely to access infrastructures and some social services. Similar to this result research undertaken in Ghana, Accra by Charles (2010) reported that development of infrastructures and social facilities which includes roads, electricity, private schools and health facilities to periurban areas as vital reimbursement. The community members who are illiterate push themselves away from utilisation of social services because of language barrier (with non-local servants) and lack of inspiration to utilise the available infrastructures and social services. Despite the fact that investors promised to construct road that connect the firm to the market thereby help nearby community to tap this opportunity, the investors failed to do so. Yet, the infrastructure become more accessible as extent of urbanization increases. This does not mean all the community members are utilising the available infrastructure and social conveniences equally and equitably.

Table 11: Socio-cultural impacts of urbanization on the peri-urban farming community

\begin{tabular}{|c|c|c|c|c|c|c|}
\hline Variable & \multicolumn{2}{|c|}{ Categories } & Total & \multicolumn{3}{|c|}{ correlation test } \\
\hline First language use & $\begin{array}{cr}\text { High(72) } & \text { Lo } \\
18.75 & 6\end{array}$ & $\begin{array}{lc}\text { 237) } & \text { Moderate(75) } \\
72 & 19.53\end{array}$ & $\begin{array}{r}384 \\
100.00\end{array}$ & $\begin{array}{l}\text { chi2 } \\
60.1053\end{array}$ & $\begin{array}{r}\mathrm{df} \\
4\end{array}$ & $\begin{array}{c}\mathrm{p} \text {-value } \\
0.000\end{array}$ \\
\hline $\begin{array}{lll}\begin{array}{l}\text { Social } \\
\text { norms }\end{array} & \text { value and } \\
\end{array}$ & $\begin{array}{l}\text { Strong (147) } \\
38.28\end{array}$ & $\begin{array}{c}\text { Weak (237) } \\
61.72\end{array}$ & $\begin{array}{r}384 \\
100.00\end{array}$ & $\begin{array}{l}\text { chi2 } \\
118.1313\end{array}$ & $\begin{array}{r}\mathrm{df} \\
2\end{array}$ & $\begin{array}{c}\text { p-value } \\
0.000\end{array}$ \\
\hline identity loss & $\begin{array}{l}\text { Yes (237) } \\
61.72\end{array}$ & $\begin{array}{l}\text { No (147) } \\
38.28\end{array}$ & $\begin{array}{r}384 \\
100.00\end{array}$ & $\begin{array}{l}\text { chi2 } \\
118.1313\end{array}$ & $\begin{array}{l}\mathrm{df} \\
2\end{array}$ & $\begin{array}{l}\text { p-value } \\
0.000\end{array}$ \\
\hline Health status & $\begin{array}{l}\text { Bad (188) } \\
48.96\end{array}$ & $\begin{array}{l}\text { Good (196) } \\
51.04\end{array}$ & $\begin{array}{r}384 \\
100.00\end{array}$ & $\begin{array}{l}\text { Chi2 } \\
222.6855\end{array}$ & $\begin{array}{r}\mathrm{df} \\
2\end{array}$ & $\begin{array}{c}\mathrm{p} \text {-value } \\
0.000\end{array}$ \\
\hline $\begin{array}{l}\text { Infrastructure and } \\
\text { facilities }\end{array}$ & $\begin{array}{l}\text { Yes(210) } \\
54.69\end{array}$ & $\begin{array}{l}\text { No(174) } \\
45.31\end{array}$ & $\begin{array}{r}384 \\
100.00\end{array}$ & $\begin{array}{l}\text { Chi2 } \\
6.7792\end{array}$ & $\begin{array}{l}\mathrm{df} \\
2\end{array}$ & $\begin{array}{l}\text { p-value } \\
0.034\end{array}$ \\
\hline
\end{tabular}

Source: Computed from own survey, 2016

\subsection{Testing the Correlation Between Variables Associate with Urbanization 4.2.1. First Language use and political participation}

The degree of political participation of the farming community can be influenced by several factors. The farming community had active and wide participation in political life at the time of homogenuous social pattern. One of the pattern upset by urban setting is the extent of first language use which in turn can affect the political participation of the farming community. Additionally, the data in table 2 indicates that more than two third (70.83\%) of the sample households expressed their agreement that they do not have political participation when first language is less used while $29.17 \%$ disagreed that they do have political participation even if they are unable to use their first language. This implies that in most cases they are unable to use their language, a barrier to the community not to express their idea freely and clearly. Therefore, not using their first language can push people back from political participation since they do not know the new invading language so that they prefer to be observers rather than actual player in the political arena. In this regard, the farming community in the urban periphery more use their first language frequently, so they are better in participating in political life. The more the community is homogenous, the more the exent of first language use and the more they participate in the political pattern. On the other hand, when the community totally get immersed in the urban setting and closer to the urban hub, it is less likely to use their first language so that their political participation becomes low. Thus, the more heterogeneous the urban population, and the less the use of first language of the farming community, and the less the political participation of the farming community. Thus, as the farming community become more marginalised in the urban area, the use of first language becomes less and vice versa is true. Even in some circumstance, the FGD discussants explained that eventhough they are ninety 
five, their interest is neglected. This deliberate political marginalization and neglection potentially can cause unnecessary political upheaval. Therefore, all stakeholders should be equally respected and their interest should be protected. Unless this community is fairly treated and compensated in the political arena, the system at large predictably become vulnerable to unforeseen political violence and uprising.

\subsubsection{Identity Loss and Eviction}

Identity of the given community can be sustained and developed through several mechanisms of protecting and promoting their identity. The community can sustain and promote Identity by protecting their identity boundary and identity markers. This enables the community to identify their cultural elements from other cultural elements using exclusion and inclusion creteria. This is partly because of their residence arrangement that is defined territorial boundary. However, this integral part of identity preservation and promotion may be disrupted when the community's stable settlement arrangement disturbed or eviction happened.

Furthermore, from table 2 it can be easily recognized that $60.94 \%$ of the respondents agreed that they have fear of social identity loss whereas $39.06 \%$ of the respondents disagreed that they do not have fear of social identity loss. The above figure should not be overlooked since the majority of the respondents expressed their agreement they do have fear of social identity loss. This statistical evidence demonstrates that a large members of the community are in the study area do have a big problem and this indicates the tragedy there ready to engulf the community. They can loss their former social arrangement due to fragmentation during eviction. The eviction as a drastic and merciless course of action dismatled the building blocks of identity that could hold and protract its existence. The community are less likely to maintain their social solidarity (linguistic and cultural affiliation) owing to cultural intermingling with the non-local settlers. Thus, eviction is more likely to cause identity loss of the community. Eviction nowadays become a great hurdle for the community that obstruct them not to sustain their existence. This community feels self alienation which is the great catastrophe prevailing in the study area that is why the above statistical evidence testifies the same reality. Thus, in order to save and protect the community from the total devastation, the urbanization process that inflating with alarming rate should be checked. In fact, the problem is not the urbanization process rather its lack of smart master plan or ugly horizontal sprawling which potentially engulf and invade a large number of hectares of farmlands and driven out many families from their living foundation. This cause political divergence between the community and ruling regime. In line with this result, Getahun (2014) reported that urbanization involves two conflicting interest from community and political elites. The community strive to maintain their local identity which interlinked with their land believing they inherited from their ancestor so eviction from this land implies identity destruction. Thus, the community resist identity frightening eviction in the course of political responses such as popular backlash, social disorder and social unrest.

Table:2. Testing the correlation between variables associates with urbanization

\begin{tabular}{|l|lll|l|l|ll|}
\hline Variable & \multicolumn{2}{|c|}{ categories } & \multicolumn{2}{c|}{ Total } & \multicolumn{3}{c|}{ correlation test } \\
\hline $\begin{array}{l}\text { Political participation } \\
\text { by freq.firstlang.use }\end{array}$ & high(72) & low(237) & moderate(75) & 384 & chi2 & df & p-value \\
& & 14.58 & 7.55 & 29.17 & 9.21 & 2 & 0.010 \\
& & & & & \\
\hline Identity loss by eviction & No (105) & Yes (279) & 384 & chi2 & df & p-value \\
& 14.06 & 46.88 & 60.94 & 5.48 & 1 & 0.019 \\
\hline
\end{tabular}

Source:Computed from own survey, 2016

\subsection{Conclusion}

\section{CONCLUSIONS AND RECOMMENDATIONS}

Based on the key findings of the study, the community in general and the family in particular had intimate and strong relationship. The family bond was very strong. More or less families were extended families. The community had strong and stiff social values, norms and community spirit. The community of the study area used to communicate invariably through same language. This community had firm social identity and affiliation. The community was socio-culturally well organised and patterned. However, after urbanization the community has undergone several transformations which includes both positive and negative patterns changes. The previous patterns have been almost eroded and invaded by the new and incompatible patterns. For example, the original socio-cultural patterns have been damaged and succeeded by the new artificial and corrupt patterns. Socio-culturally, the community has been fragmented and dismantled. The first language use drops off from time to time. This weakens the social bond of the community since language was used as bonding tool. The weakening of the local social values, norms and community spirit and the loss of the local identity become the worrisome crisis. Generally speaking, the community have been victimised since they lost their fundamental patterns of life. 


\subsection{Recommendations}

In the conclusion sections, several issues related to the peri-urban farming community and urbanization impacts that affected the essential patterns of the community were clearly addressed. In this study, key problems caused by the uncontrolled urbanization process were identified. This peri-urban farming community deserves immediate and long term remedies. Therefore, all stakeholders including the community, government, investers, scholars and individuals should work collectively to alleviate the ever increasing impacts of unbridled urbanization.

Since the problems are associated with the lease system and masterplan, the concerned body particularly the government should execute the viable and plausible activities that save the community from total devastation. Accordingly, the key suggestions forwarded as follows:

1. As much as possible, necessary cautionary measures should be taken before eviction. Awareness should be created among the community on how to adapt new urban life style.

2. The community's interest should be clearly identified and considered instead of forceful eviction. The debate and dialogue forum should be arranged and organized thereby every key stakeholders can attend the forum just to create common understanding.

3. The protection and promotion of socio-cultural patterns like use of first language should be enhanced. The community should not be obliged to communicate through other language. The community deserves social services like education and health centers with their own language speaker so as to avoid unnecessary misunderstanding. Adequate schools from kindergarton upto preparatory school need to be built.

4. The community should make every possible effort to protect and uphold the owned social values, norms and community spirit. Moreover, the community need to adapt some new modern social skills and psychological skills to survive and flourish in the modern world.

5. All necessary care should be given not to evict the community haphazardly rather due attention should be given to the community's preferences where to live and how to live. For example, the community desires to preserve their local identity. Thus, the community need to inhabit at one place. The government can organize such resettlement arrangement without fragmenting the community.

6. Each and every urban centers need to have its own masterplan that helps to manage the resource and protect defined boundary of its own. The masterplan should not be over ambitious, but it should be smart masterplan that does not affect the neighboring villages or urban setting. Smart masterplan can be designed just inclusively by incorporating or embracing the interest of all key stakeholders.

7. Lastly, scholars of different expertise background can scrutinize the undetected dimension of the urbanization impacts that was not addressed by this study.

\section{REFERENCES}

[1] Achamyeleh Gashu. 2014. Land Tenure in the Changing Peri-Urban Areas of Ethiopia. The Case of Bahir Dar City, International Journal of Urban and Regional Research, Article first published online. 11 APR 2014, DOI: 10.1111/1468-2427.12123. www.ijurr.org.accessed on semptember 25,2015.

[2] Adu Ampong, E., F. 2008. Socio-economic Transitions. Changing Livelihoods in the Periurban Interface: A case study in Peri-urban interface of Kumasi, A draft Report.

[3] Alaci, D.S.A. 2010. Regulating Urbanization in Sub-Saharan Africa through Cluster Settlements. Lessons for Urban Mangers in Ethiopia. Theoretical and Empirical Researches in Urban management 5(14).

[4] Anonymous. n.d. Political economy and urbanization. The case of capitalism system.

[5] Bhatta, B. 2010. Analysis of Urban Growth and Sprawl from Remote Sensing Data. Advances in Geographic Information Science, DOI 10.1007/978-3-642-05299-6_2, C Springer-Verlag Berlin Heidelberg.

[6] Bluman, G.A. 2009. A step by step elementary approach. Elementary statistics seven edition. MC GRAW HILL. Higher education:published by McGraw-Hill campanies, Inc.,1221 Avenus of the Americas , New York, NY10020: Page 589-625:785

[7] Bryant, D. C. 2007. 21st century sociology: A reference handbook / coeditors in chief Clifton D. Bryant, Dennis L. Peck. Rolf A.Janke .volume one. Traditional and Core Areas

[8] Caswell, T. C. 2001. U.S.History:Immigration and Migration, Urbanization. New York State High School Regents Exam Prep Center. www.regentsprep.org/regents/ushisgov/themes/immigration/urban.htm;

[9] Redman, L., Charles, and Jones, S., Nancy. 2004. The Environmental, Social, and Health Dimensions of Urban Expansion. International Institute for Sustainability and the Consortium for the Study of Rapidly Urbanizing Regions. Arizona State University.

[10] Charles, Y. O. 2010. "Effects of Rapid Urbanization On Livelihoods In The Peri-Urban Areas Of Accra, Ghana" Electronic Theses, Treatises and Dissertations. Paper 4634. http://diginole.lib.fsu.edu/etd/4634. 
[11] Dejene Nigusie. 2011. Rapid urban expansion and its implications on livelihood of farming communities on peri-urban area: the case of sebeta town. MA Thesis, Addis Ababa University, Addis Ababa.

[12] Department for International development. 2008. Who Can Help the Peri-urban Poor? : Adoption and Impact of Livelihood Activities on Community Members in the Kumasi Peri-Urban Interface - R8090 Revised Research Report 4.

[13] Douglas, Wester. 2001. Human settlement development-V.I.Per urbanization; Zones of rural-urban transition . www.ontarionature.org.

[14] Economic Commission for Africa. 2006. Land Policy in Africa. A Framework of Action to Secure Land Rights, Enhance Productivity and Secure Livelihoods, Issued paper presented for Consultative Workshp, 27 to 29 March 2006 on Economic Commission of Africa

[15] Enychlopedia of life support system -UNESCO. 2001. http://www.eolss.net/Eolss. sample All Chapter. aspx.

[16] Ermias Abera. 2009. Urban Development-induced Displacement: Prospective and Challenges of Real Estate Development on the Livelihoods of Rural Communities: the case of Lega Tafo Lega Dadi, MA theses. Addis Ababa University, Addis Ababa.

[17] Fayera Abdisa. 2005. Urban Expansion and Livelihood of the Peri-urban Agricultural Community: the case of Addis Ababa, MA Thesis, Addis Ababa University.

[18] Federal Negarit Gazeta. 2005. Expropriation of Land Holding for Public Purposes and Payments of Compensation. Proclamation No. 455/2005, P. 3124-3132

[19] Feyera A. and Terefe D. 2010. The Demographic Transition and Development in Africa. The Unique Case of Ethiopia. Urbanization and Changing Livelihoods: The Case of Farmers' Displacement in the Expansion of Addis Ababa. pp 215-235. DOI 10.1007/978-90-481-8918-2_11

[20] Flanagan, W. G. 2010. Urban Sociology: Images and Structure, Fifth Edition. Published by Rowman \& Littlefield Publishers, Inc. A wholly owned subsidiary of The Rowman \&Littlefield Publishing Group, Inc. 4501 Forbes Boulevard, Suite 200, Lanham,Maryland 20706. http://www.rowmanlittlefield.com.

[21] Getahun Banti. 2014. A nation without a city, a Blind without a cane. North east Africa studies, ISSN 0740-9133. Cities as centers of civilization, 160-161 and Gathering storm, 176-177.

[22] Giddeons, A. 2001. The complete resource package in sociology. sociology $4^{\text {th }}$ edition. polity. page (574). Anthony Giddeons with assistance of Karen Birdlaw.BlackBell publishing company, 2001.

[23] Gosaye Bekele. 2007. Beyond the Formal Urban System. Learning from Informal Settlements in Adama city, Ethiopia. Mechanisms and Rationale for their emergence, expansion and potential, MSc)

[24] Hall, T. 2006. Routledge contemporary Human Geography series. Urban Geography $3^{\text {rd }}$ edition , (102103). London and New York published 2006 and reprinted 2007.

[25] Haregewoin Bekele. 2005. Urbanization and Urban Sprawl, Stockholm http://www.sprawlcity.org/defining.html.

[26] Herbst, Jeffrey. 2009. Population Change, Urbanization and Political Consolidation. The Oxford Handbook of Contextual Political Analysis, Edited by Robert E.Goodin and CharlesTilly.

[27] Kalkidan B. 2001. Informal Transformation at the Urban Fringe of Addis Ababa. MSc

[28] Kemal, O. and Enwere, C. 2012. Urbanization and its Political Challenges in Developing Countries. Eurasian Journal of Business and Economics, 5(10), 99-120.

[29] Leulsegged Kasa, Gete Zeleke, Dawit Alemu, Fitsum Hagos and Andreas Heinemann. 2011. Impact of urbanization of Addis Abeba City on peri urban environment and livelihoods. Msc socio-economic researcher, sekota Dry land Agricultural research centre of Amhara Regional Agricultural Research Institute.

[30] Machnachie, R. A. and Binns, J. A. 2006. Sustainability under Threat? The Dynamics of Environmental Change and Food Production in Peri-urban Kano, Nigeria. Journal of Land Degradation and Development, Vol. 17, pp. 159-171.

[31] Mekonen Wube. 2002. The Impact of Urban Expansion on the land Tenure and Livelihood of Rural Households. The Case of Mekanissa III housing project, Addis Ababa, Ethiopia. 2002. MSc)

[32] Mandere, N. M., B. Ness and Anderberg, S. 2010. Peri-urban development, livelihood change and household income: A case study of peri-urban Nyahururu, Kenya. Journal of Agricultural Extension and Rural Development 2 (5): 73-83.

[33] Mara, Gittleman. 2009. Urban Expansion in Addis Ababa: Effects of the Decline of Urban Agriculture on Livelihood and Food Security. A paper presented at the United Nations $17^{\text {th }}$ Commission on Sustainable Development.

[34] Marshall, F. L, Waldman, H. MacGregor, L. Mehta and P. Randhawa. 2009. On the Edge of Sustainability: Perspectives on Peri-urban Dynamics: Social, Technological and Environmental Pathways to Sustainability, Working Paper 35, Brighton: STEPS Centre. 
[35] Martin, Adams. 2008.Tenure Security, Livelihoods and Sustainable Land Use in Southern Africa, Paper presented at the SARPN conference on Land Reform and Poverty Alleviation in Southern Africa.

[36] Martinez, D., Yadira, M., Mendez. 2007. Effects of Urban growth in the process of Impoverishment of Campesino's Households Living in Peri-urban Areas: The case of Mexico City, PhD theses. University of Queensland, Australia.

[37] Melesse M. 2005. City Expansion, Squatter Settlements and Policy Implications in Addis Abeba: The Case of Kolfe Keranio Sub-City, Working papers on population and land use change in central Ethiopia, nr. 2, Serie A, Nr. 9, Trondheim.

[38] Nutter, Michael. 2010. What are the political, social and economical effects of urbanization?. https://answers.yahoo.com/question/index?qid.

[39] Nicodemus, M. Mandere1, Barry, Ness1 and Stefan, Anderberg. 2010. Peri-urban development, livelihood change and household income: A case study of peri-urban Nyahururu, Kenya. Journal of Agricultural Extension and Rural Development Vol. 2 (5) pp.73-83.

[40] Oromia Bureau of Finance Economic Development. 2010. Socio-economic Profile Report of Oromia Special Zone Surrounding Finfinne. Addis Ababa.

[41] Oromia Urban Planning Institute. 2008. Structural Plan of Sebata Town Document Prepared by Oromia Urban Planning Institute. Addis Ababa

[42] Resnik, David, B. 2010. Urban Sprawl, Smart Growth and Deliberative Democracy. American Journal of Public Health | October 2010, Vol 100, No. 10 National Institute of Environmental Health Sciences, National Institutes of Health,Box 12233, Mail Drop CU 03, Research Triangle Park, NC 27709 (email: resnikd@niehs.nih.gov).

[43] Ritzer, George. 2011. Sociological Theory Eighth Edition. Published by McGraw-Hill, a business unit of The McGraw-Hill Companies, Inc., 1221 Avenue of the Americas, New York, NY 10020. Previous editions (C) 2008, 2004, and 2000. p (7)

[44] Roe, B. 2009. Urban Challenges in Addis Ababa. PhD and Master Theses from Department of Urban Design and Planning, Faculty of Architecture and Fine Art, NTNU, Trondheim, Norway in the period 2000-2008.

[45] Samuel Gebreselassie. 2006. Land, Land Policy and Smallholder Agriculture in Ethiopia: Options and Scenarios. Paper prepared for the Future Agricultures Consortium meeting at the Institute of Development Studies 20-22 March 2006.

[46] Satterthwaite, D. and C. Tacoli. 2003. The urban part of rural development: the role of small and intermediate urban centres in rural and regional development and poverty reduction, IIED.

[47] Stolley, S. K. 2005. The Basics of Sociology. Basics of the Social Sciences. GREENWOOD PRESS .Westport, Connecticut. London.

[48] Tadele T. 1999. The Impact of Urban Development on Peasant Community in Ethiopia: The Case of Yeka Tafo Peasant Association, a Community in the Vicinity of the Ethiopian Capital, Addis Abeba, Disposed by the Ayat Real Estate Development Project. MA thesis in Social Anthropology, Addis Ababa University.

[49] Thuo, A.D.M. 2010. Community response to land use transformation in Nairobi rural-urban fringe, Kenya. University of Waikato, Field Action Report.

[50] Wubeshet Berhanu. 2002. Urban Policies and the Formation of Social and Spatial Patterns in Ethiopia. The Case of Housing Areas in Addis Ababa. 2002. Ph.D. Thesis.

[51] UN-Habitat. 2008. Ethiopian Urban Profile. United Nations Human Settlements Programme Regional and Technical Cooperation Division.

[52] UN-HABITAT. 2010. State of the World Cities 2010/2011: Bridging the Urban Divide. United Nations Human Settlements Programme, Nairobi, Kenya.

[53] UN Habitat. 2010. "Urban Sprawl Now a Global Problem", a report on state of World Cities 2011/2012.

[54] Urban-sociological theories. php. http://www.sociologyguide.com/industrial-and-urban-society.accesseed on may 10, 2015.

[55] Urbanization-The Social Impacts Of Urbanization - Family, Family, and Household - JRank Articles :http://family.jrank.org/pages/1732/Urbanization-Social-ImpactsUrbanization.html\#ixzz3n9An8MGo: visited on semptember 15, 2015.

[56] Victor, C. Obinna, Opuene, B. Owei and Ikechi O. Okwakpam. 2010. Impacts of Urbanization on the Indigenous Enclaves of Port Harcourt and Concomitant Policy Measures. Volume:5 /Issue: 3 /page No,: 172-186. DOI: 10, 3923/sscience. 2010. 172-186 